\title{
The effect of Cold Plasma (Combined Argon-Helium Gases) on Microbial Contamination and Physicochemical Properties of Minced Sheep Meat
}

\author{
Farideh Peidaei ${ }^{1}$, Anoosheh Sharifan $^{1 *}$, Ramona Massoud ${ }^{2}$ \\ ${ }^{1}$ Department of Food Science and Technology, Science and Research Branch, Islamic Azad University, Tehran, Iran; \\ 2Department of Food Research, Standard Organization, Tehran, Iran
}

Received Oct. 19, 2018; Accepted Jul. 16, 2019

\begin{abstract}
Introduction: The demand for consuming healthy food has increased due to the developed techniques for assessing food safety and detection of microbial contamination. Among the non-thermal processing methods, using cold plasma along with atmospheric pressure, has received much attention. The present study aims to investigate the effect of cold plasma, the combination of argon and helium gases, on the reduction of microbial load and physicochemical changes in minced sheep meat. Methods: In this study, minced sheep meat was subjected to 36 cold atmospheric plasma treatments with different time intervals (3, 6, and $9 \mathrm{~min}$ ) and argon-helium gas ratios (1:8 and 2:7). Microbial counts and physiochemical properties (moisture, color, free fatty acids, and $\mathrm{pH}$ ) were measured according to the Iranian national standards. Results: Both ratios of argonhelium (1:8 and 2:7) were effective in reducing the microbial load of minced sheep meat via cold atmospheric plasma in all exposure intervals (3, 9 and $12 \mathrm{~min}$ ). However, the argon-helium ratio of 2:7 and an exposure time of $12 \mathrm{~min}$, was the most effective combination in decreasing microbial contamination. Conclusion: Our findings elucidated that the cold plasma processing method was effective in reducing the microbial load of minced sheep meat. Furthermore, we concluded that both parameters of time and gas composition affect microbial load reduction by cold plasma. J Med Microbiol Infec Dis, 2019, 7 (1-2): $12-18$.
\end{abstract}

Keywords: Sheep meat, Argon, Helium, Cold plasma.

\section{INTRODUCTION}

Red meat, due to high protein content and the balanced combination of vital nutrients such as essential fatty acids, vitamins, and minerals, plays a significant role in the human diet. One of the characteristics of sheep meat is the high content of fat $(6 \%)$, which makes it more palatable [1]. Minced meat, compared to non-minced meat, is much more vulnerable to microbial contamination. When the microbial contamination level in minced meat reaches to $10^{7}-10^{9}$ CFU per gram, the organoleptic changes would appear [2].

Meat corruption occurs via three mechanisms, including microbial growth, fat oxidation, and degradation by autolytic enzymes. These mechanisms lead to color loss, slime formation, unfavorable taste and smell, and tissue softness, which make the product unpleasant and unacceptable for customers [3]. Bacterial growth is the leading cause of food corruption, and also one of the significant concerns of the food industry [4]. The conventional storage methods such as refrigeration and using modified atmosphere packaging (MAP) are not enough for preserving fresh and unprocessed meat. Therefore, there is a need for a novel non-thermal method that could prevent microorganisms' growth and protect the quality of meat simultaneously [5].

Plasma, as a novel and advanced technology, is applied in many industries, including the food industry. Recent studies have shown that atmospheric cold plasma can be useful for food preservation [6-8]. Plasma is an ionized gas in the semi-neutral state, containing ions, electrons, and non-charged particles like atoms, molecules, radicals, and ultraviolet photons. Electrons and photons are light components of a molecule compared to the other particles. The term "plasma" is used to describe a state of matter in which heavy components (ionized or non-ionized particles) caused by raising the energy content of gas [3]. The application of atmospheric pressure plasma is a novel method that ensures food safety during the process [9]. It was demonstrated that applying plasma at atmospheric pressure on salted pork meat and eggshells helped to maintain the quality of food [10]. Furthermore, the application of low-temperature atmospheric plasma resulted in a reduction of microbial contamination in chicken meat [11].

${ }^{*}$ Correspondence: Anoosheh Sharifan

Department of Food Science and Technology, Science and Research Branch, Islamic Azad University, Tehran, Iran, 1477893855.

Email: rahmanish3@mums.ac.ir

Tel: +98 (21) $44867154 \quad$ Fax: +98 (21) 66460700 
Also, atmospheric pressure plasma inactivated the Listeria monocytogenes in chopped meat and increased the shelf life [10]. Plasma processing causes cell death via two main mechanisms, electrostatic breakdown and membrane oxidation [8]. In electrostatic breakdown, the electric charge accumulates in the membrane surface, so the total electric force overcomes the tensile strength, which keeps the structure of Gram-negative bacteria membrane, and hence the membrane destruction occurs. The tensile strength of the membrane relates to the murein or peptidoglycan layer, which is thicker in Gram-positive bacteria $(15-18 \mathrm{~nm})$ compared to Gram-negatives $(2 \mathrm{~nm})$. In the second mechanism, the cell membrane damage and the cell contents leak out due to the membrane oxidation and the high energetic ions, radicals, and reactive substances produced during the plasma process. Reactive radicals, produced directly in plasma method, penetrate the cell surface and also reactive oxygen species (ROS) and finally induce damaging effects on cells by reacting with different macromolecules [8].

The growing demand for fresh crops and safe foods with minimum processing and without microbial contamination is a massive challenge for the food industry. Hence, modern methods of preserving food and eliminating microorganisms without affecting the quality, have attracted much attention. Using cold plasma for microbial decontamination without the thermal side-effects can potentially replace the traditional methods [11].

In the present study, the effect of using cold plasma on the reduction of microbial load and physicochemical changes in minced sheep meat was evaluated.

\section{MATERIAL AND METHODS}

Preparation of meat. The sheep meat was provided from a meat supplier in Tehran and transferred to Cool Plasma Laboratory, Tehran, Iran laboratory with ice packs under sanitary conditions, $24 \mathrm{~h}$ after slaughtering and during the time of rigor mortis. After having microbial and physicochemical experiments, $100 \mathrm{~g}$ portions of minced meat were packed in autoclaved polyethylene plastic bags and stored at $4{ }^{\circ} \mathrm{C}$ for future use.

Physicochemical tests. The moisture content, color, free fatty acids content, and $\mathrm{pH}$ of the samples were measured according to the Iranian national standards No. 745,743 , and 1028 [12-14].

pH value. Amounts of $20 \mathrm{~g}$ of minced sheep meat were mixed with $100 \mathrm{~mL}$ of distilled water, filtered after $10 \mathrm{~min}$, and the $\mathrm{pH}$ of the aqueous phase was measured [14].

Measuring the fat and fatty acid contents. The fat content of samples was measured after the fat extraction from the dried sample using n-hexane or light petroleum (the water content was previously measured in accordance with Iranian national standards No. 745) [12]. The solvent was then removed by evaporation, and the remaining fat was dried and weighed. Then, neutralized ethyl alcohol was added to the obtained fat, and warmed up while gradually titrated with sodium hydroxide until the white color turned to pale pink (the end of titration) [13].
Moisture content. Moisture content was measured according to Iranian national standards No.745 [12]. The meat sample $(5 \mathrm{~g})$ was put in a pre-weighed flat aluminum dish and transferred to a hot oven $\left(101 \pm 1^{\circ} \mathrm{C}\right)$ for $3-4 \mathrm{~h}$. Then the dried sample was placed in a desiccator having silica gel as a desiccant agent. After $1 \mathrm{~h}$, the dish was weighed, and the moisture content was calculated as follows: Moisture $(\%)=\frac{\mathrm{W} 2-\mathrm{W} 3}{\mathrm{~W} 2-\mathrm{W} 1} \times 100$ where $\mathrm{W} 1=$ weight of the empty dish; W2 = weight of dish and sample; W3 = weight of the dish and dried sample.

Color test. The changes in the color of the treated samples were analyzed in comparison to the control sample using spectrophotometer (flex color model) coupled with the HunterLab system. The device was controlled with white, black, and red tiles before the test. The color indicators, a (redness), b (yellowness), and L (brightness) were determined by placing the specimens in the device reservoir [7].

Plate Count Agar (PCA). One of the suitable methods for determining the total microbial contamination of foods is the total count test. The mixed culture method was applied. In Plate Count Agar (Merck, Germany); the plates were incubated at $32-30^{\circ} \mathrm{C}$ for $24 \mathrm{~h} \mathrm{[15].}$

Statistical analysis. The statistical analysis was performed using Duncan's multiple range test in Minitab 18 software. One-way analysis of variance (ANOVA) was used to compare the means. For statistical analysis, the data were considered as three replicates. The statistical results related to the study of the intensity and duration of flow, the independent t-test was used for comparing the means with control sample. Also, a significance level of 0.05 was considered for all tests.

\section{RESULTS}

The combination of two parameters, time and gas ratio, was evaluated in the experiments on minced sheep meat samples.

Based on the results of ANOVA, the average meat color index remains constant despite changes in the gas composition and exposure time. Therefore, variations in the plasma gas ratio (Fig. 1) and plasma exposure time (Fig. 2) had no significant effects on color indices $(\mathrm{L}, \mathrm{a}, \mathrm{b})$ of the minced sheep meat $(P>0.05$, level of $95 \%)$.

Based on the results of ANOVA, fatty acid content of minced sheep meat was significantly affected by exposure time (Fig. 3) and plasma gas composition (Fig. 4) $(P<0.05$, level of $95 \%$ ).

Based on the results, the average moisture content of minced shee pmeat changed significantly with plasma gas composition (Fig. 5) as well as plasma exposure time (Fig. 6) $(P<0.05$, level of 95\%). Compared to control sample, all cold plasma-treated samples showed a reduced moisture content.

As results showed, the meat $\mathrm{pH}$ index varied significantly with changes in plasma exposure time (Fig. 7) and plasma gas composition (Fig. 8) and $(P<0.05$, level of $95 \%)$. 
In accordance with the results, the average microbial load index of the meat varied significantly depending on duration of exposure (Fig. 9) and the type of plasma gas composition (Fig. 10) $(P<0.05$, level of 95\%). In all cold plasma-treated samples, the microbial load was decreased. The results showed that the argon-helium ratio of 2:7 with an exposure time of $12 \mathrm{~min}$, was the most effective treatment.

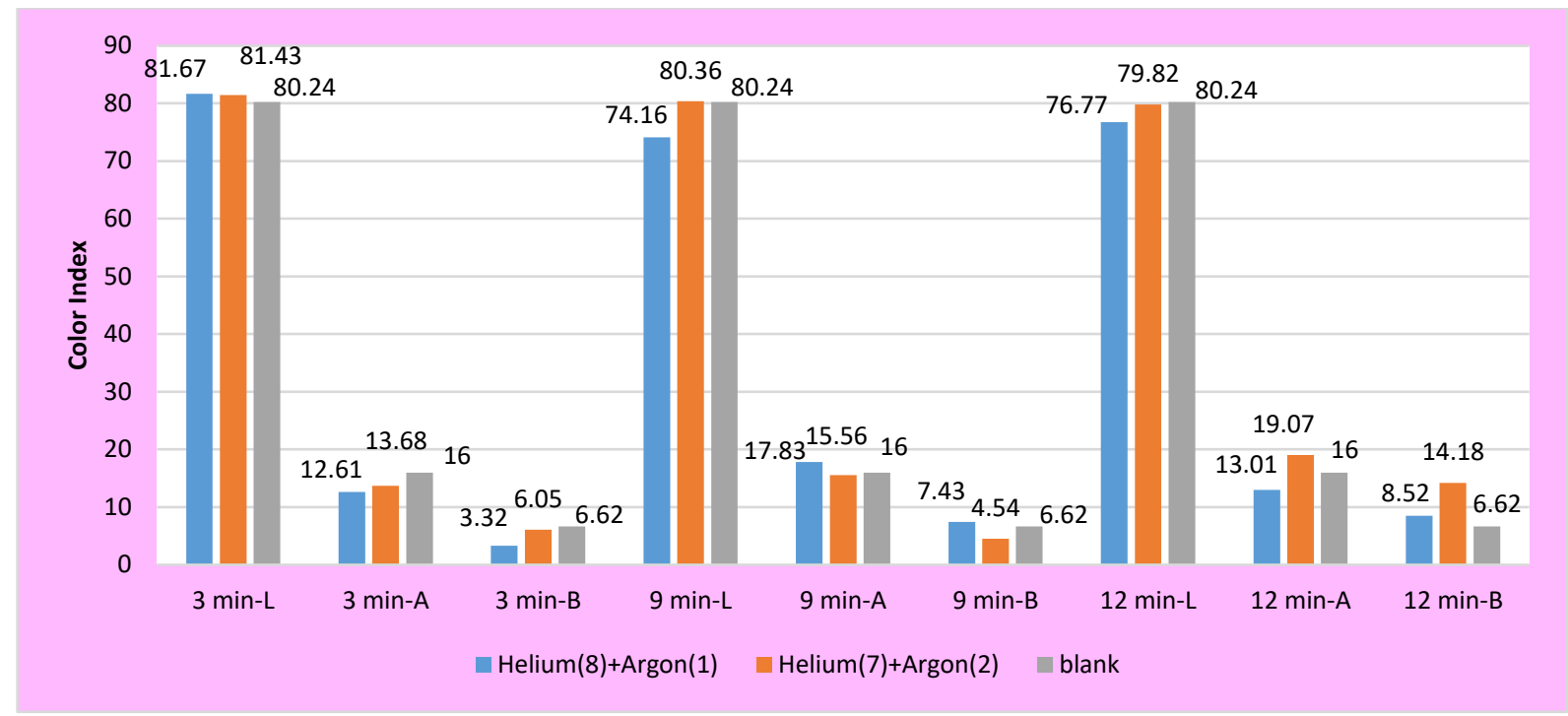

Fig. 1. The effect of plasma gas composition on the color of minced sheep meat. Color indicators, $A *($ redness), B*(yellowness) and $\mathrm{L} *$ (brightness)

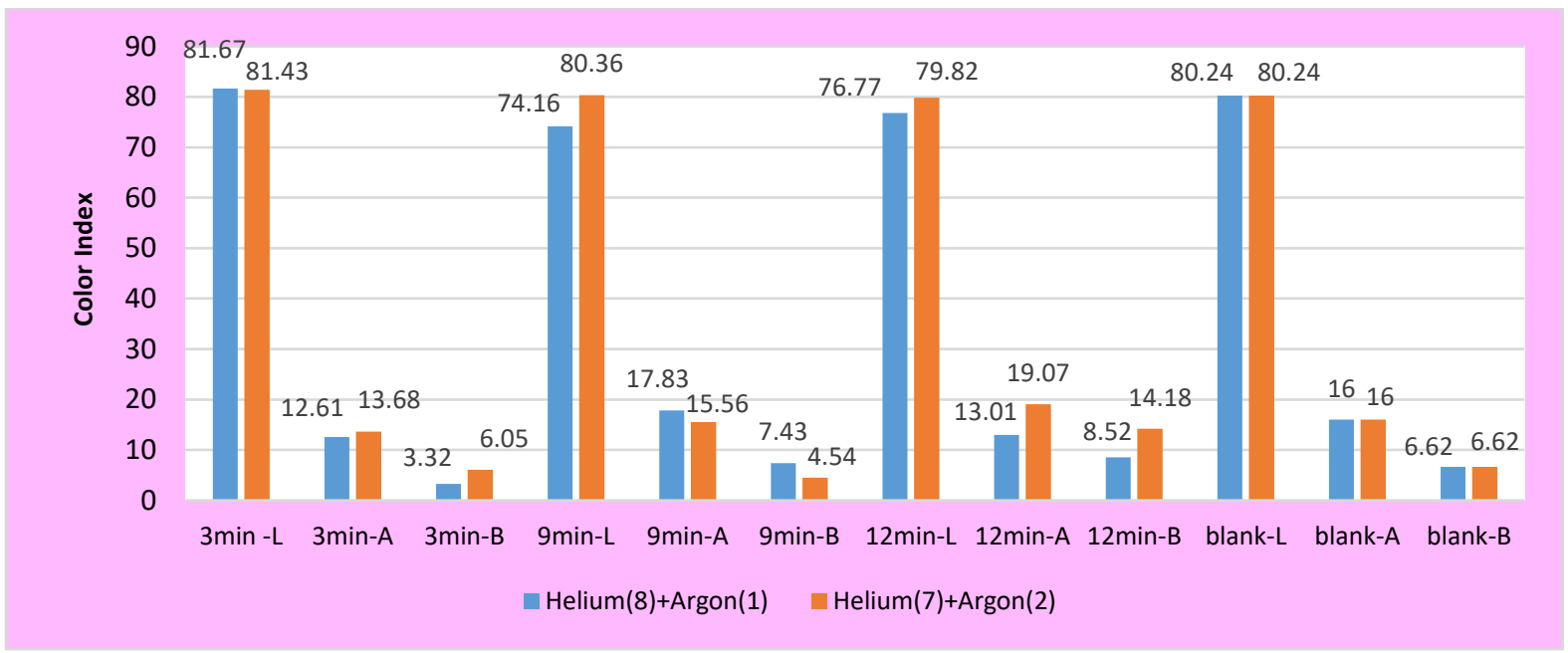

Fig. 2. The effect of plasma duration on the color indexes of minced sheep meat. Color indicators, $A^{*}$ (redness), $B^{*}$ (yellowness), and $L^{*}$ (brightness)

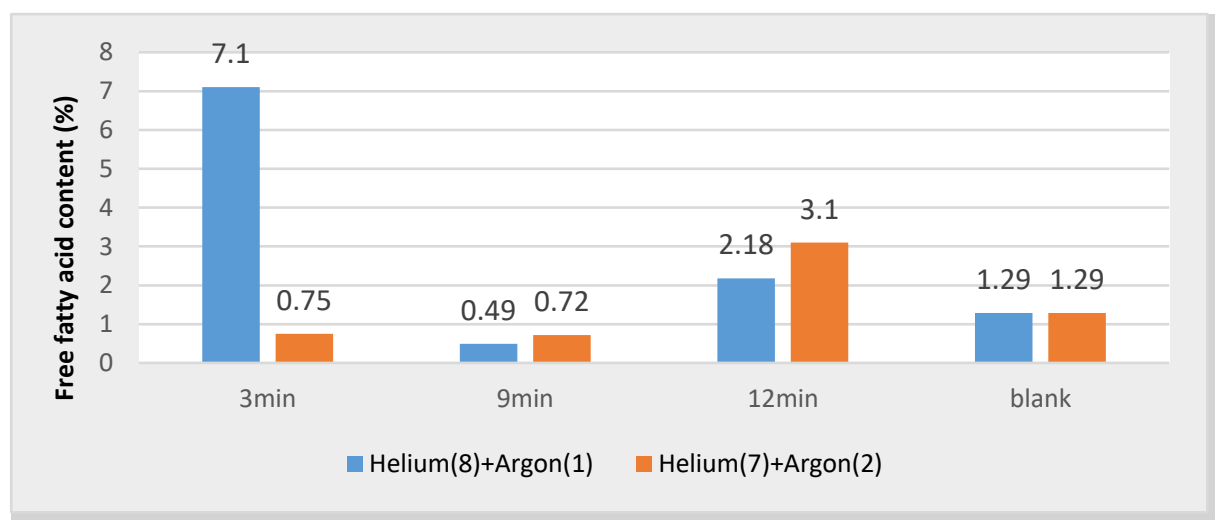

Fig. 3. The effect of plasma exposure time (3,9 and $12 \mathrm{~min})$ on free fatty acid content of minced sheep meat 


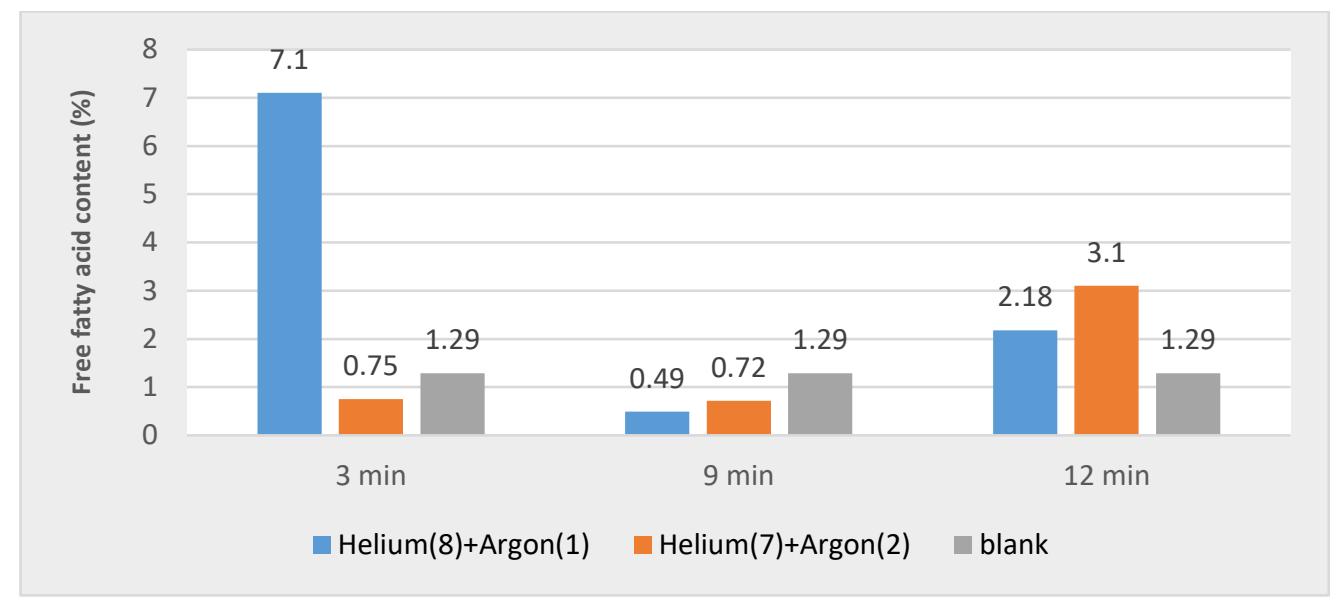

Fig. 4. The effect of plasma gas composition on free fatty acid content of the minced sheep meat

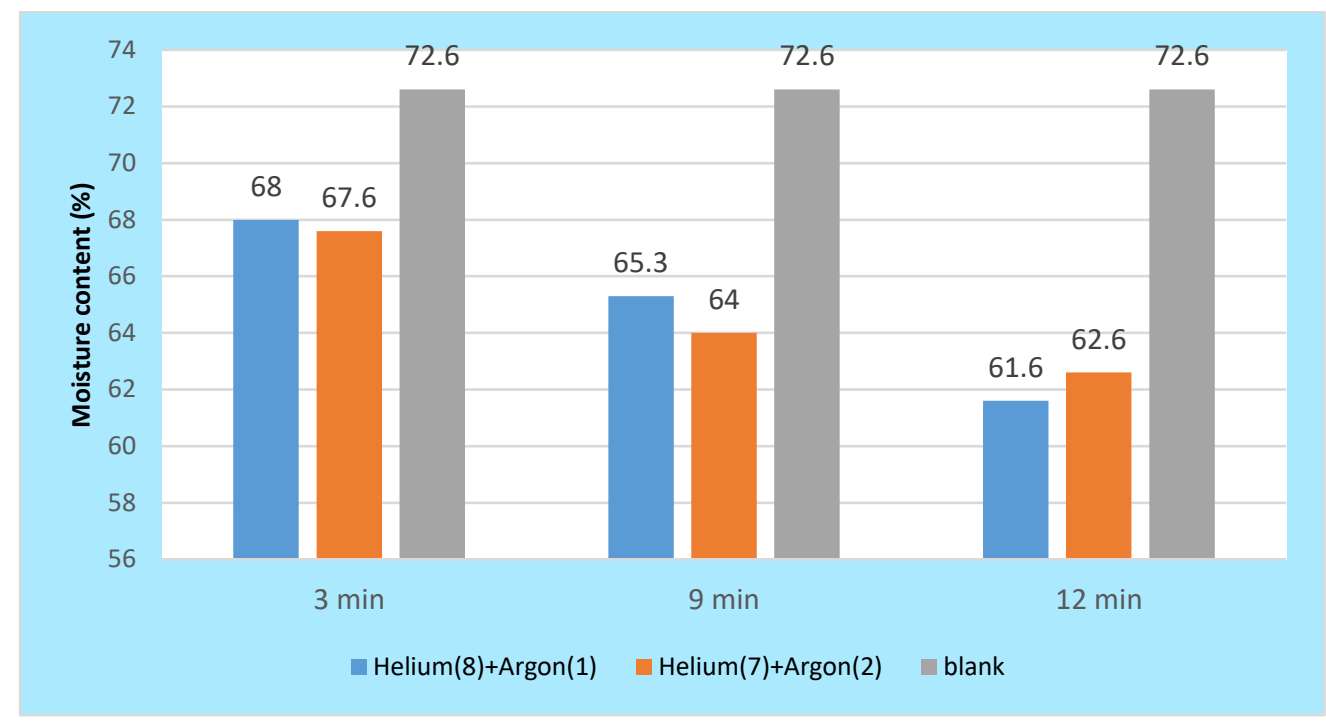

Fig. 5. The effect of plasma gas composition on the moisture content of minced sheep meat

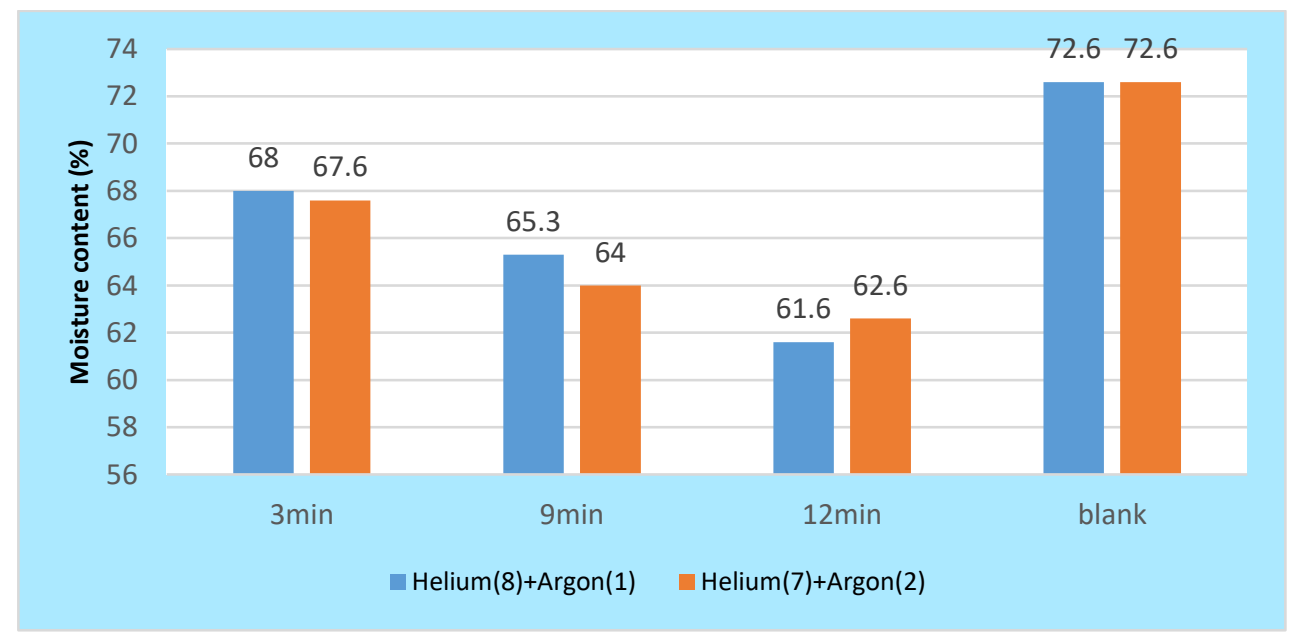

Fig. 6. The effect of plasma exposure time on the moisture content of minced sheep meat 
Peidaei et al.

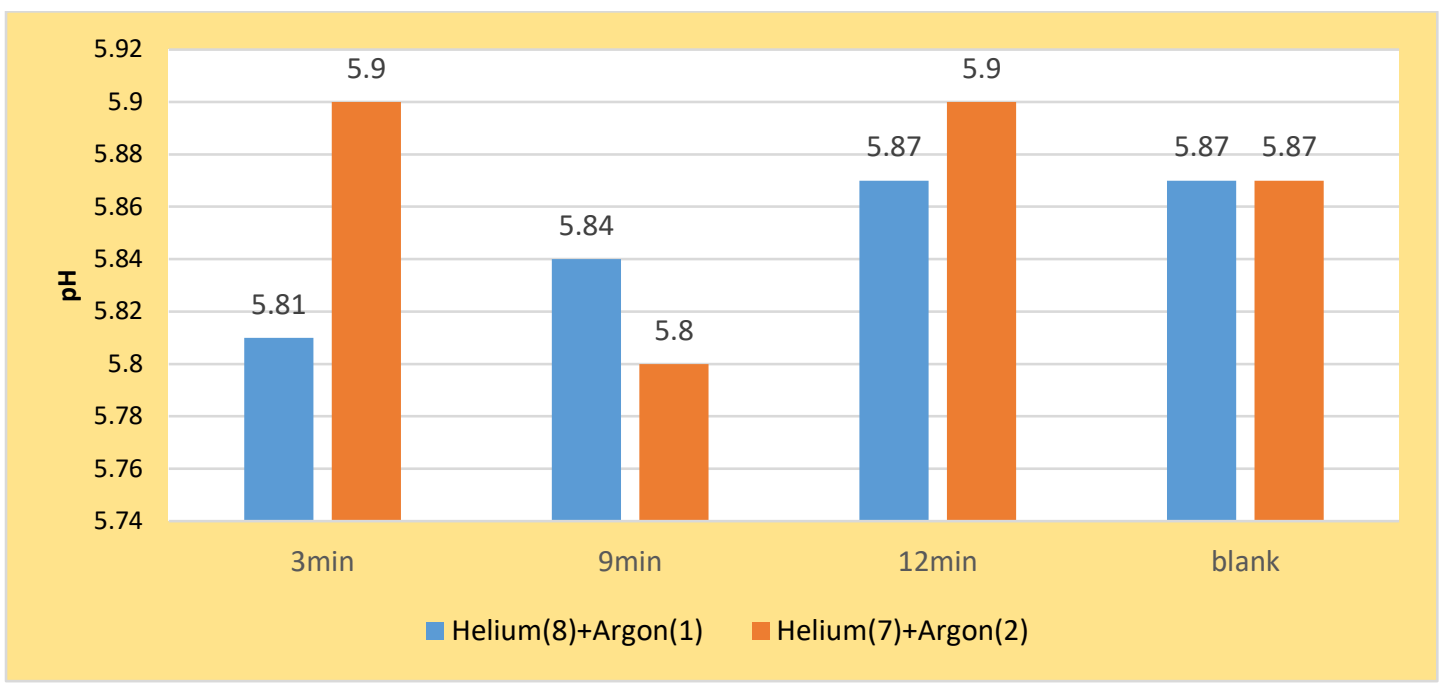

Fig. 7. The effect of plasma exposure time on $\mathrm{pH}$ changes in minced sheep meat

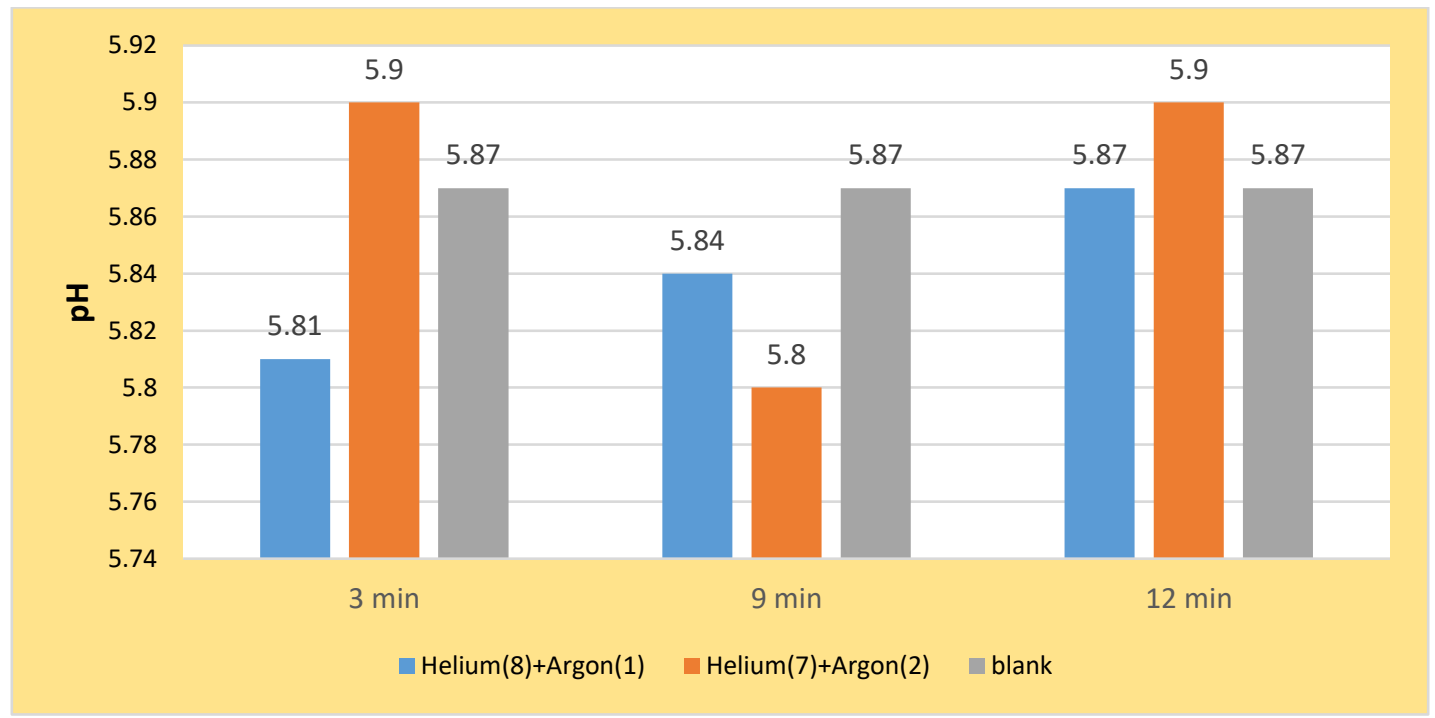

Fig. 8. The effect of plasma gas composition on $\mathrm{pH}$ changes in minced sheep meat

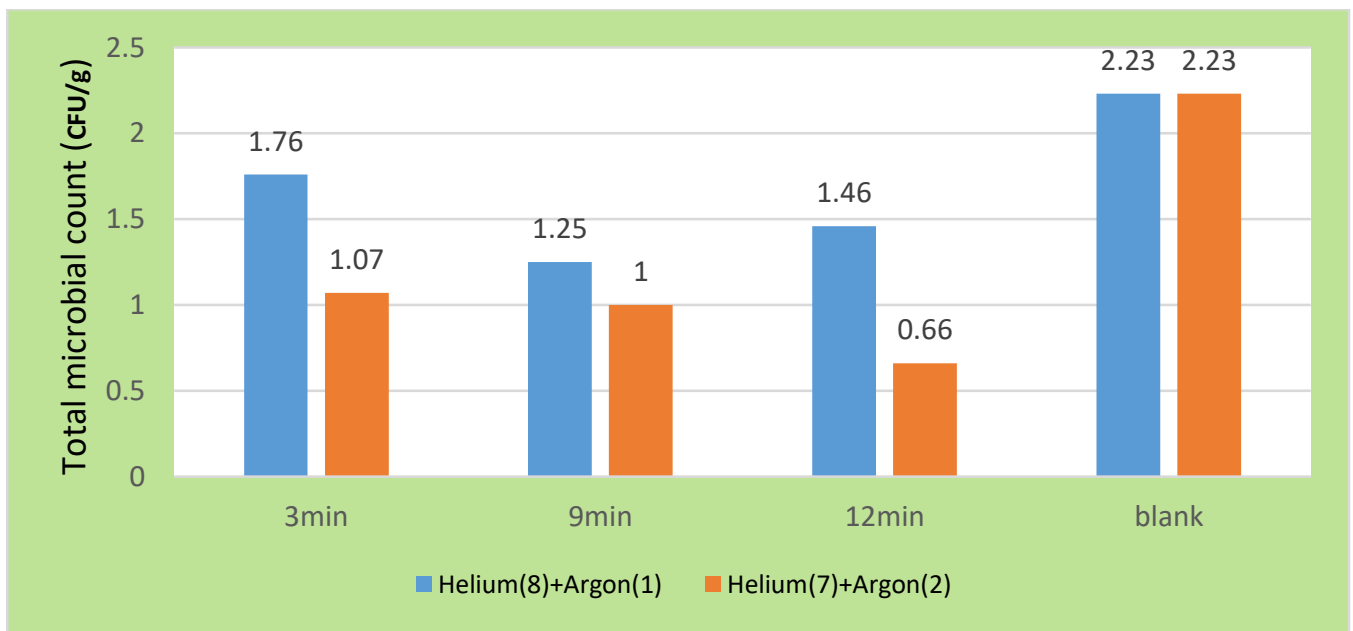

Fig. 9. The effect of plasma exposure time on logarithmic changes in the microbial load of minced sheep meat 


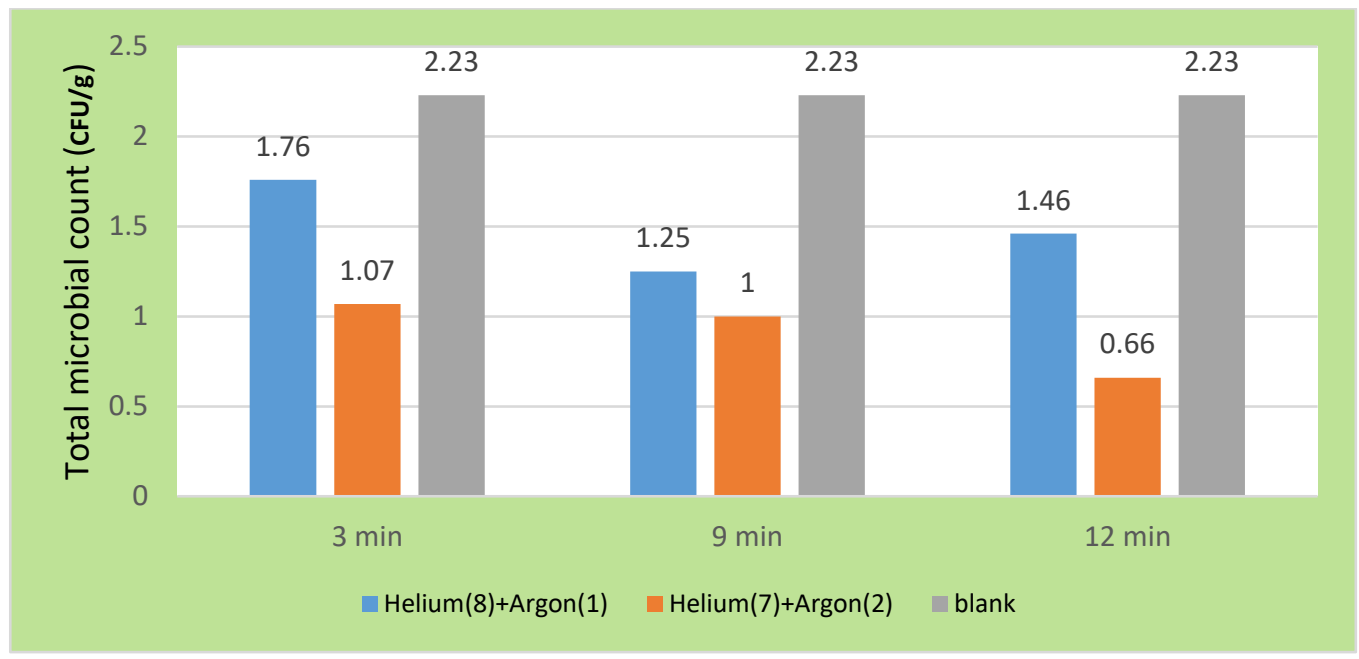

Fig. 10. The effect of plasma gas composition on logarithmic changes in the microbial load of minced sheep meat

\section{DISCUSSION}

There are some reports on the physicochemical properties and microbial load of fresh meat and meat products following cold plasma processing. The amount of Listeria monocytogenes, Escherichia coli, and Salmonella Typhimurium in pork meat were about 1-2 logarithmic cycles and 2-3 logarithmic cycles, respectively after helium and helium/oxygen plasma treatments $[9,16]$. Similarly, in our project, the microbial load of the minced meat significantly decreased after plasma treatments in different gas composition and duration of exposure. The results elucidated that for microbial load reduction in minced sheep meat, both combinations of argon-helium with ratios of 1:8 and 2:7 were effective in all exposure time intervals (3, 9 and $12 \mathrm{~min}$ ). However, the argon-helium ratio of $2: 7$ with an exposure time of $12 \mathrm{~min}$ was the most effective treatment. In addition to reducing the microbial load, the ratio of 2:7 argon-helium caused fewer changes in physiochemical properties of minced sheep meat.

The antimicrobial activity of cold plasma technique in food depends on various factors such as plasma sources, food structures, microorganisms exposure to the plasma ions, temperature, and exposure time of the process. Helium and Argon are the preferred gases due to having high thermal conductivity, rich ultraviolet emission spectrum, and lower operating discharge voltage in atmospheric pressure [17]. Also, these two plasma gases are rich in charged particles, which cause the damage of bacterial cell surface [8]. In this study, the extensive surface area of minced meat could enhance the efficacy of cold plasma treatment. Our research showed that plasma gas composition and exposure time did not affect the color of minced sheep meat, which is in agreement with the results of a similar study by Zhou and colleagues [5]. However, the average fatty acid content of minced sheep meat was significantly affected by plasma gas composition and exposure time $(P<0.05)$. The oxidative damage of fatty acids in meat induces lipid peroxidation, which promotes not only the production of off-flavors and off-odors, but also the reduction of food shelf life [18]. Lipid oxidation as a complex process consists of free radical chain mechanisms that culminate in the synthesis of fatty acyl peroxides or other oxidation products [4].

In this study, the $\mathrm{pH}$ values changed significantly $(P<0.05)$ with changes in plasma gas composition and exposure time, which might be attributed to the change of fatty acids content. Based on the results, the moisture content of minced sheep meat reduced significantly $(P<0.05)$ with the plasma gas composition as well as exposure time, which is similar to the results of other studies on meat preservation techniques [4, 5].

Eventually, for applying plasma technique in the meat industry, it is essential to pay attention to different factors such as plasma sources, food matrix, types of microorganisms, temperature, and exposure time of the process.

\section{ACKNOWLEDGMENT}

We would like to thank Department of Food Science and Technology, Tehran Science and Research Branch, Islamic Azad University of Iran for supporting this research project.

\section{CONFLICT OF INTEREST}

The authors declare that there are no conflicts of interest associated with this manuscript.

\section{REFERENCES}

1. Rokni N. Meat Science and Technology. 3th Ed., Tehran University Press; 2003; 1-6 [In Persian].

2. Akitsu T, Ohkawa H, Tsuji M, Kimura H, Kogoma M. Plasma sterilization using glow discharge at atmospheric pressure. Surf Coat Tech. 2005; 193 (2): 29- 34.

3. Bouhdid S, Abrini J, Amensour M, Zhiri A, Espuny M.J, Manresa A. Functional and ultrastructural changes in Pseudomonas aeruginosa and Staphylococcus aureus cells 
induced by Cinnamomum verum essential oil. J Appl Microbiol. 2010; 109 (1): 1139-1149.

4. Dave D, Ghaly AE. Meat spoilage mechanisms and preservation techniques: a critical review. Am J Agric Biol Sci. 2011; 6: 486-510.

5. Zhou GH, Xu XL, Liu Y. Preservation technologies for fresh meat-a review. Meat Sci. 2010; 86:119-128.

6. Deng S, Ruan R, Mok CK, Huang G, Lin X, Chen P. Inactivation of Escherichia coli on almonds using nonthermal plasma. J Food Sci. 2007; 72:62-66.

7. Hosseini E, Asadi GH, Malarreza L. Maintenance of white meat; 3rd National Conference on Food Security; 2013 Sep 1315; Savadkooh, Iran; 2013.

8. Joshi S, Gearson S. Nonthermal Dielecteric-Barrier Discharge plasma -Induced Inactivation Involves Oxidative DNA Damage and membrane Lipid Peroxidation in Escherichia coil. Food Sci Tech. 2011; 55 (3): 1053-1062.

9. Kim B, Yun H, Jung S, Jung Y, Jung H, Choe W, Jo C. Effect of atmospheric pressure plasma on inactivation of pathogens inoculated onto bacon using two different gas compositions. Food Microbiol. 2011; 28: 9-13.

10. Lee H, Jung H, Choe W, Ham J, Lee J. Inactivation of Listeria monocytogenes on agar and processed meat surfaces by atmospheric pressure plasma jets. Food Microbiol. 2011; 28 (8): 1468-1471.
11. Saba V, Ramezani KH, Hashemi H. Bacterial sterilization using Dielectric barrier discharge plasma in atmospheric pressure. MJIRI. 2013; 3: 199-196.

12. Iranian national standards No. 745. Meat and meat products Determination of moisture content - Test method. Institute of Standards and Industrial Research of Iran; 2003.

13. Iranian national standards No. 743. Meat and meat products Determination of free fat content - Test method. Institute of Standards and Industrial Research of Iran; 2003.

14. Iranian national standards No. 1028. Meat and meat products - Measurment of $\mathrm{pH}$ - Reference test method. Institute of Standards and Industrial Research of Iran; 2007.

15. Sha'bani SH, Toomari I. Quality control of food microbiology. Publications of the Science and Research Branch of Islamic Azad University. 2nd ed. Tehran: Iran; 2013. P. 340355.

16. Lerouge S, Wertheimer MR, Yahia L. Plasma sterilization: a review of parameters mechanisms and limitations. Plasmas Polym. 2001; 6: 175-188.

17. Moisan M, Barbeau J, Crevier M, Pelletier J. Plasma sterilization. Methods and mechanisms. Pure Appl Chem. 2002; 74: 349-358.

18. Moreau M, Orange N, Feuilloley MGJ. Non-thermal plasma technologies: new tools for bio-decontamination. Biotech Adv. 2008; 26: 610-617. 